\title{
DAYA TAMPUNG BEBAN PENCEMAR SUNGAI BADUNG DI DESA DAUH PURI KOTA DENPASAR DENGAN MODEL QUAL2KW
}

\author{
Dody Setiawan $^{1 *}$, I G B Sila Dharma ${ }^{2)}$, I Wayan Budiarsa Suyasa ${ }^{3)}$ \\ ${ }^{1)}$ P3E Bali dan Nusa Tenggara - KLHK \\ 2)Jurusan Fakultas Kelautan dan Perikanan Universitas Udayana \\ 3) Jurusan Kimia Fakultas MIPA Universitas Udayana \\ *Email : dodysetia@gmail.com
}

\section{ABSTRACT \\ POLLUTION LOAD CAPACITY OF BADUNG RIVER AT DAUH PURI VILLAGE, DENPASAR TOWN USING QUAL2KW MODEL}

Badung River is flow through two regencies of Badung and Denpasar that has $25.17 \mathrm{~km}$ length. People actually use Badung River for tourism, irrigation, drainage system and as the exile of wastewater from all activities along the river. The water quality of Badung River has exceeded the threshold limits. Therefore, It is needed to determinate the carrying capacity of Badung river. Because of the pollution, the water quality has degraded. The objective of this research is knowing the sources of pollution and load capacity of Badung river at Dauh Puri village using Qual2kw model, to define that amount of pollutant that are allowed to exile in Badung River. The water quality parameter that analyzed is BOD, COD, and TSS. This research divided into three segments, and four scenarios of simulations to know allowed loading rate of pollutant along the river. The callculates and allocate pollutant reduction levels necessary to meet approved water quality standards. The result of simulation using Qual2kw showing that BOD has over its limit, meanwhile for COD parameter, the loading rate is between 536,21 to $1360,32 \mathrm{~kg} /$ day and TSS loading rate between 2235,92 to $4252,90 \mathrm{~kg} / \mathrm{day}$.

Keywords: Badung River, Qual2KW 5.1, Loads Capacity, Water Quality

\section{PENDAHULUAN}

Salah satu komponen dari lingkungan kita yang mampu memberikan kelangsungan hidup adalah air. Air merupakan sumberdaya alam yang mutlak dibutuhkan bagi kehidupan makhluk hidup. Salah satu sumber air berasal dari sungai, namun seiring dengan pembangunan, sungai turut terkena salah satu dampak buruk berupa limbah dari berbagai aktivitas yang dibuang ke dalamnya. Kualitas air sungai dipengaruhi oleh kualitas pasokan air yang berasal dari daerah tangkapan sedangkan kualitas pasokan air dari daerah tangkapan berkaitan dengan aktivitas manusia yang ada di dalamnya (Wiwoho, 2005).

Sungai Badung merupakan bagian dari daerah aliran sungai (DAS) Badung yang mengalir membelah Kota Denpasar, dengan luas DAS + 37,7 $\mathrm{km} 2$ dan panjang alur $+25,17 \mathrm{~km}$ dengan hulu sungai berada $12 \mathrm{~km}$ di sebelah utara Kota Denpasar dan bermuara di Teluk Benoa (Wiarta, 2008). Pemanfaatan DAS Badung sesuai dengan Master Plan dari Kota Denpasar pada umumnya adalah sebagai sarana irigasi umum bagi 7 kecamatan yang terdiri dari 31 desa yang dilewati oleh DAS Badung (As-syakur et al, 2010).
Kualitas air sungai Badung telah melewati baku mutu yang dipersyaratkan. Data kualitas air Sungai Badung pada tahun 2012 menunjukan kadar BOD berkisar 9,65-10,04 mg/l dan COD berkisar 17,12$25,10 \mathrm{mg} / \mathrm{l}$ (Eryani dkk, 2014). Menurut Peraturan Pemerintah Nomor 82 Tahun 2001 tentang Pengelolaan Kualitas Air dan Pengendalian Pencemaran Air, kadar BOD $_{5}$ pada tahun 2012 mengindikasikan kelas air sungai badung berada pada kelas 4 (kelas air dengan kadar BOD maksimum $12 \mathrm{mg} / \mathrm{L})$. Sedangkan kadar COD pada tahun yang sama mengindikasi air sungai Badung berada pada kelas 3 (kelas air dengan kadar COD maksimum 50 $\mathrm{mg} / \mathrm{L}$ ). Berdasarkan fakta ini, fungsi Sungai Badung telah mengalami penurunan kualitas, karena terkontaminasi limbah domestik, persawahan dan komersial. Beberapa parameter pencemar yang telah melampaui baku mutu yaitu: BOD, COD, Fosfat, dan Total coliform (BLH Provinsi Bali, 2013). Melihat pada kenyataan tersebut, maka diperlukan upaya pengelolaan. Salah upaya untuk pengelolaan Sungai Badung dengan menetapkan daya tampung beban pencemar. Beban pencemar air sungai di Sungai Badung dapat ditentukan dari sumber pencemarnya point source dan non point source yang di modelkan dengan program Qual2kw. Penelitian ini juga 
bertujuan untuk menghitung daya tampung beban pencemar Sungai Badung dan mengidentifikasi kegiatan/aktivitas yang berpotensi menjadi sumber pencemar yang mempengaruhi kualitas air Sungai Badung.

\section{METODOLOGI}

\subsection{Penentuan Wilayah Studi}

Penelitian ini dilakukan di Sungai Badung yang masuk di wilayah Kota Denpasar, Desa Dauh Puri. Waktu penelitian dilakukan bulan September Nopember 2016 yang dibagi kedalam 3 segmen dengan panjang sungai $\pm 6.08 \mathrm{~km}$.

\subsection{Pengumpulan Data}

Data yang di gunakan dalam penelitian ini berupa data primer dan data sekunder. Data primer di peroleh saat survei lapangan yang meliputi lebar sungai, kedalaman sungai, kecepatan arus, debit sungai, sumber pencemar dan kualitas air hasil sampling. Pengukuran debit dilakukan dengan Velocity Method. Pada metode ini, debit (Q) suatu aliran diperoleh sesuai persamaan (1) dan (2): (Sugiharto, 2014).

$\mathrm{Q}=\mathrm{V} \times \mathrm{A}$

Dimana:

$\mathrm{Q}=$ debit aliran $\left(\mathrm{m}^{3} /\right.$ detik $)$

$\mathrm{V}=$ Kecepatan aliran (m/detik)

$\mathrm{A}=$ luas penampang basah $\left(\mathrm{m}^{2}\right)$

= lebar sungai X kedalaman sungai

Pengambilan sampel dilakukan dengan dua cara, yaitu pemeriksaan in situ meliputi $\mathrm{pH}$ dan temperatur. Pengukuran Sampel air sungai untuk parameter, BOD, COD dan TSS di analisa ke Laboratorium Analitik Universitas Udayana. Data sekunder meliputi peta administrasi, data kualitas air dari BLH Provinsi Bali sedangkan data klimatologi di peroleh dari BMKG Wilayah III Denpasar.

\section{HASIL DAN PEMBAHASAN}

Daya tampung beban pencemar dapat ditentukan dengan melalukan berbagai tahapan:

\subsection{Pembagian Segmen Sungai}

Segmentasi sungai diperlukan untuk memudahkan dalam menentukan titik sampling serta upaya penurunan beban pencemar yang masuk, ke badan air Sungai Badung yang terbagi dalam tiga segmen dapat dilihat pada Gambar 1.

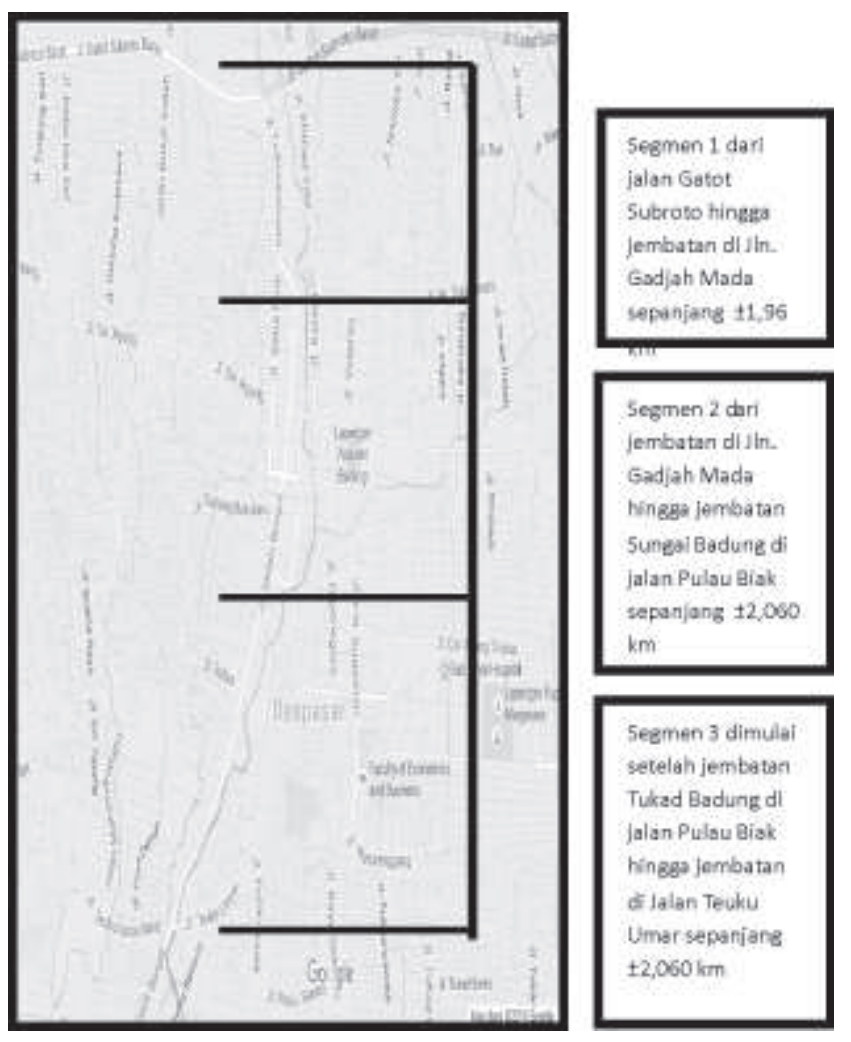

Gambar 1.Pembagian segmen Sungai Badung

\subsection{Pembangunan Verifikasi Model atau Kalibrasi Data}

Langkah penggunaan model Qual2kw dengan mengentry data primer dan data sekunder pada lembar kerja Qual2kw. Dilanjutkan dengan kalibrasi data lalu verifikasi model yang bertujuan untuk memperoleh data model sesuai dengan data sebenarnya untuk kemudian dilanjutkan dengan analisis data pada program Qual2kw.

\subsection{Sumber Pencemar}

Penentuan sumber pencemar pada penelitian ini dibatasi berdasarkan batas DAS dan batas administrasi. Wilayah penelitian tersebut kemudian dibagi menjadi tiga segmen/reach berdasarkan area pencemaran untuk memudahkan proses identifikasi penggunaan lahan dan inventarisasi sumber pencemaran. Identifikasi penggunaan lahan dan inventarisasi sumber pencemaran dilakukan bersamaan karena saling terkait.

Berdasarkan peta rencana tata ruang yang dicocokkan dengan peta penggunaan lahan dan verifikasi lapangan menunjukkan aktivitas pada reach 1 didominasi oleh permukiman dan usaha. Aktivitas lain seperti rumah sakit dan anak sungai yang juga turut memberikan kontribusi pada penambahan limbah ke badan sungai. Pada reach 2 aktivitas yang dominan adalah pemukiman dimana 
ada juga sebuah pasar dan anak sungai dan reach 3 aktivitas yang dominan adalah permukiman dan usaha seperti warung makan dapat ditemukan dalam jumlah yang sedikit. Aktivitas permukiman ini merupakan sumber pencemar tak tentu yang dominan di ketiga reach berpotensi menimbulkan pencemaran pada badan sungai karena saluran pembuangan masing-masing aktivitas tersebut langsung menuju badan sungai dan letaknya yang berada di sepanjang sungai.

\subsection{Simulasi Kualitas Air}

Skenario Simulasi ini dibagi berdasarkan empat model simulasi skenario dengan tujuan untuk mendapatkan daya tampung serta mengetahui kondisi badan air sumber pencemar dari berbagai kondisi. Teknik simulasi dapat dilihat pada Tabel 1.

\subsubsection{Simulasi skenario 1}

Simulasi pada skenario 1 merupakan simulasi dengan kondisi eksisting baik pada kualitas air di sungai maupun data sumber pencemar, dimana data yang diinput sesuai dengan hasil dari pembentukan model. Hasil dari model simulasi skenario 1 tiap parameter dapat dilihat pada Gambar 2, 3 dan 4.

Berdasarkan hasil simulasi skenario 1 , kandungan parameter BOD dari hulu hingga hilir berada diatas baku mutu air Kelas II, yaitu baku mutu parameter BOD sebesar $3 \mathrm{mg} / \mathrm{L}$. Hal ini ini berhubungan dengan banyaknya masukkan dari beban BOD yang berasal dari limbah domestik Parameter COD dan TSS di semua titik sampling Sungai Badung tidak melebihi batas ambang baku mutu yang diijinkan.

Tabel 1.Skenario Teknik Simulasi

\begin{tabular}{lcccc}
\hline No & Kondisi di Hulu & Data Sungai & Sumber Pencemar & Kondisi Air Sungai \\
\hline 1 & Eksisting & Eksisting & Eksisting & Model \\
2 & Eksisting & Eksisting & Tidak Ada sumber pencemar & Model \\
3 & Baku Mutu Air Kelas II & Baku Mutu Air Kelas II & TidakAda sumber pencemar & Model \\
4 & Baku Mutu Air Kelas II & Baku Mutu Air Kelas II & Trial and error & Baku mutu Air Sasaran Kelas II \\
\hline
\end{tabular}

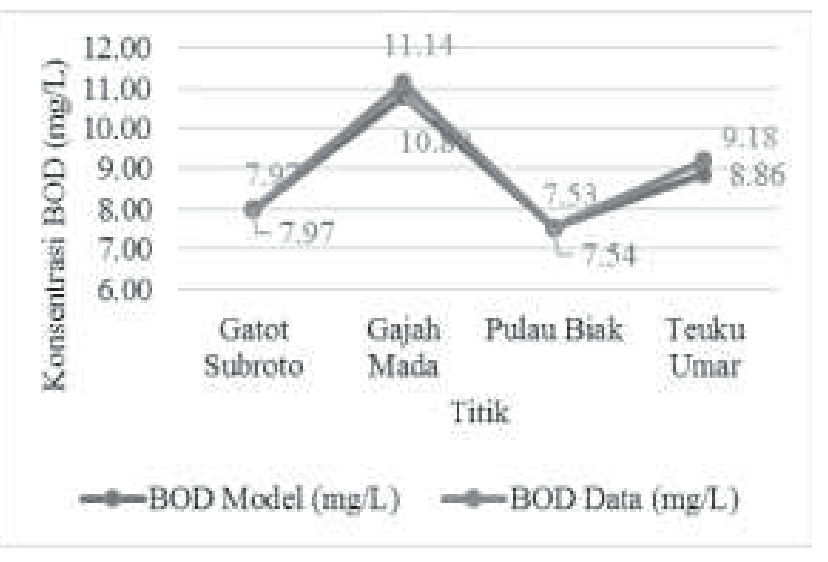

Gambar 2.Simulasi Skenario 1 Parameter BOD

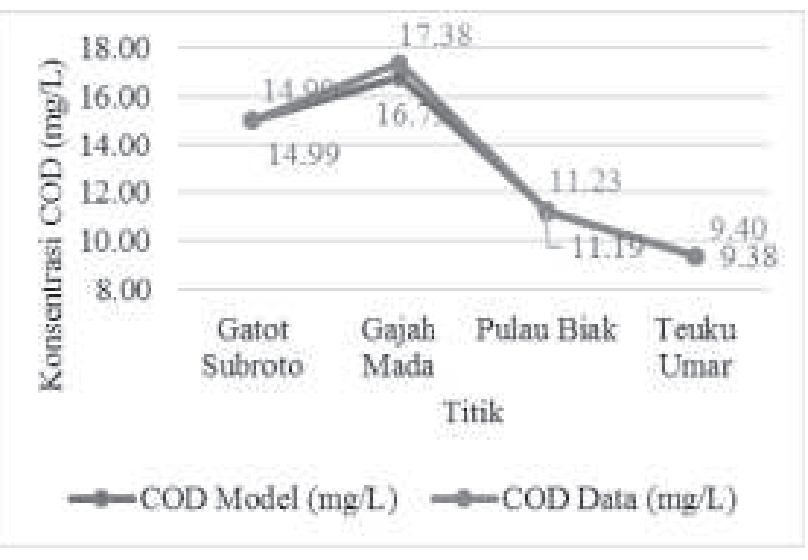

Gambar 3.Hasil Simulasi Skenario 1 Parameter COD

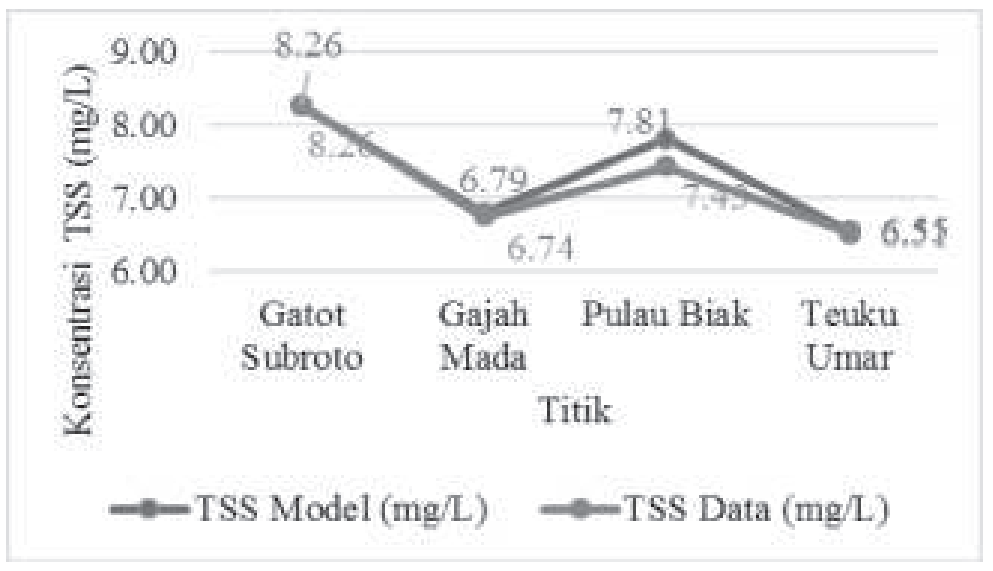

Gambar 4. Simulasi Skenario 1 Parameter TSS 


\subsubsection{Simulasi Skenario 2}

Pada skenario ini kualitas air di Sungai Badung menggunakan data existing, sementara itu diasumsikan tidak ada sumber pencemar yang masuk ke Sungai Badung, baik limbah industri maupun limbah domestik (dari simulasi ini dapat diketahui self purification sungai). Hasil dari model simulasi skenario 2 tiap parameter dapat dilihat pada Gambar 5, 6 dan 7. Simulasi skenario 2 adalah kualitas badan air dari hulu hingga hilir dikondisikan tidak tercemar oleh sumber pencemar baik point source maupun non point source. Kondisi di hulu diasumsikan tetap disesuaikan dengan kondisi eksisting.

Hasil simulasi skenario 2 pada gambar 5 kandungan parameter BOD dari titik 1 hingga titik 4 masih berada diatas baku mutu air Kelas II yaitu sebesar $3 \mathrm{mg} / \mathrm{L}$. Hal ini disebabkan oleh kondisi di badan Sungai Badung sudah tercemar oleh

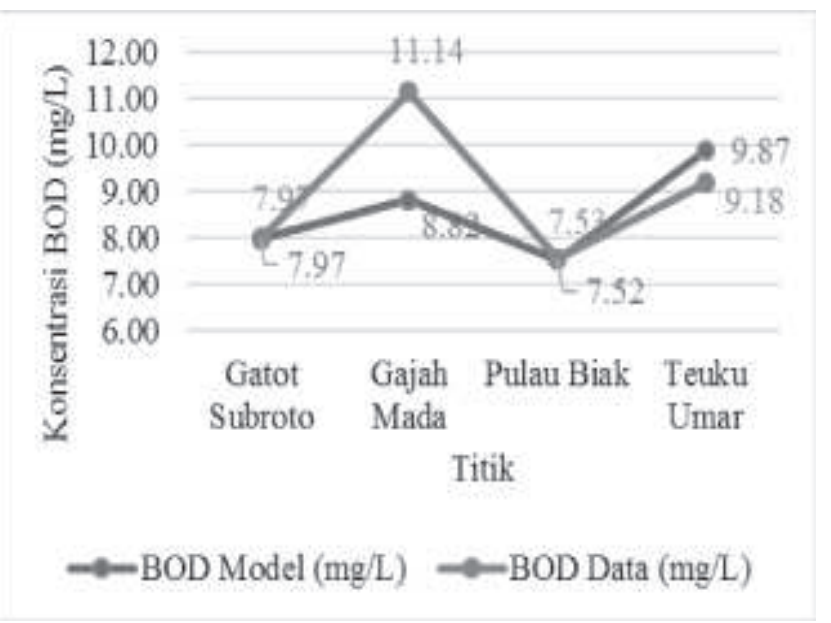

Gambar 5.Simulasi Skenario 2 Parameter BOD masukkan dari limbah lain di bagian hulu Sungai Badung. Parameter COD (Gambar 6), di semua titik pantau berada di bawah baku mutu air Kelas II yaitu sebesar 0,2 mg/L. Termasuk untuk parameter TSS (gambar 7), kandungan TSS pada Sungai Badung tidak melebihi batas ambang baku mutu yang diijinkan.

\subsubsection{Simulasi Skenario 3}

Pada skenario ini kualitas air Sungai Badung diasumsikan memenuhi baku mutu air Kelas II, sedangkan untuk sumber pencemar diasumsikan tidak ada sumber pencemar yang masuk ke Sungai Badung, baik limbah industri maupun limbah domestik. Hasil dari simulasi skenario 3 ini untuk mengetahui kondisi self purification sungai ketika sungai berada pada batas ambang baku mutu. Hasil dari model simulasi skenario 3 tiap parameter dapat dilihat pada Gambar 8, 9 dan 10.

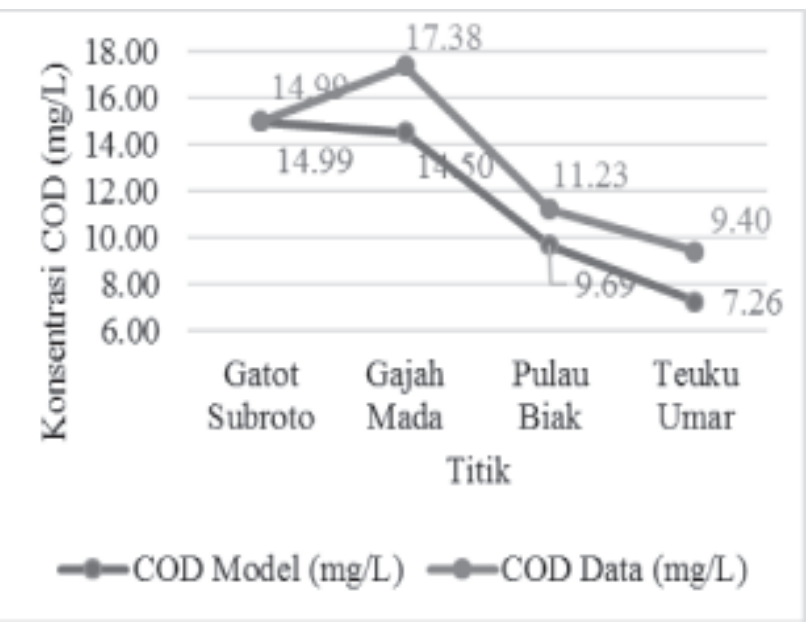

Gambar 6. Simulasi Skenario 2 Parameter COD

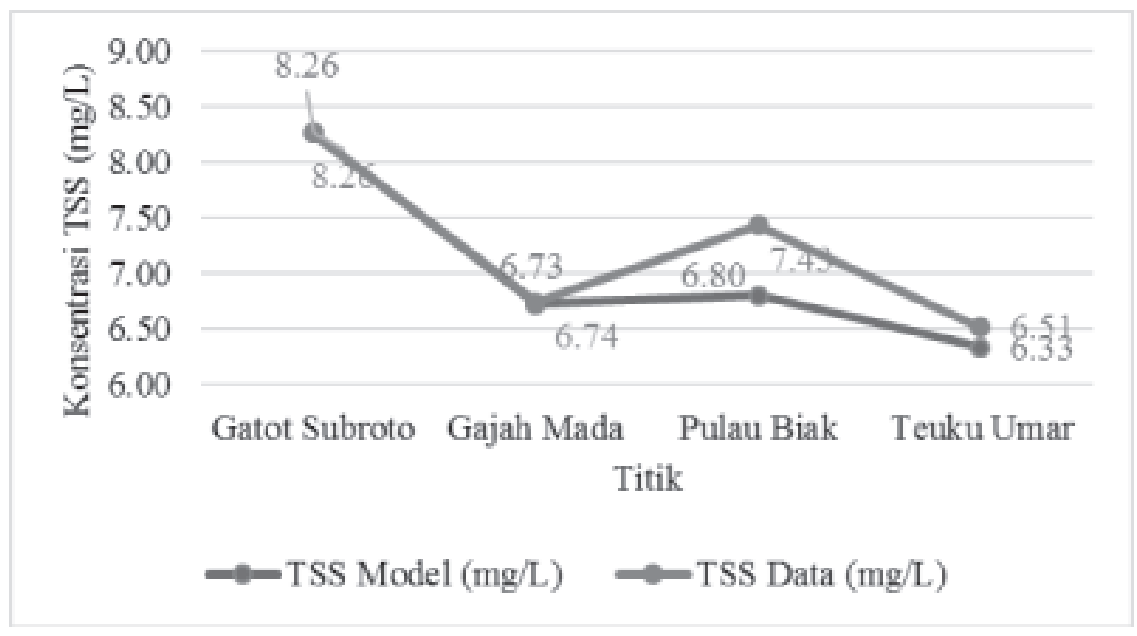

Gambar 7. Simulasi Skenario 2 Parameter TSS 


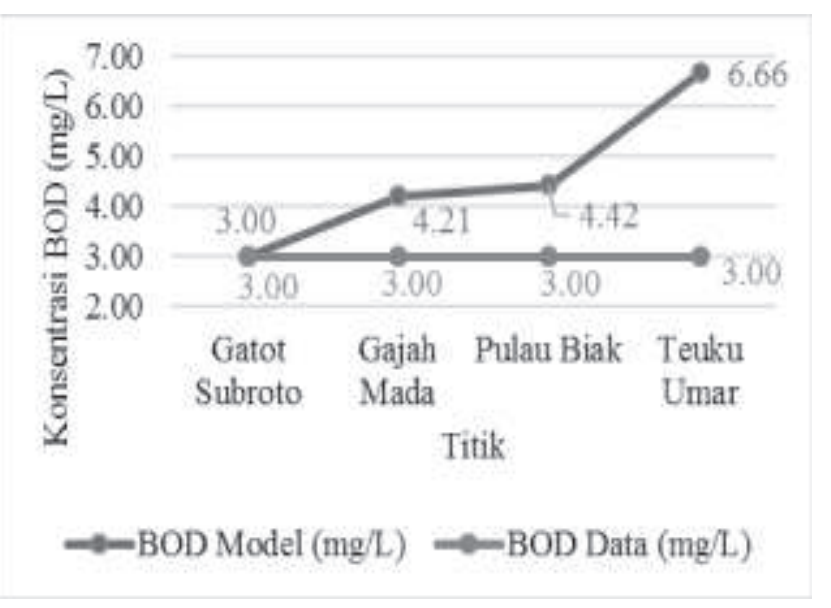

Gambar 8.Simulasi Skenario 3 Parameter BOD

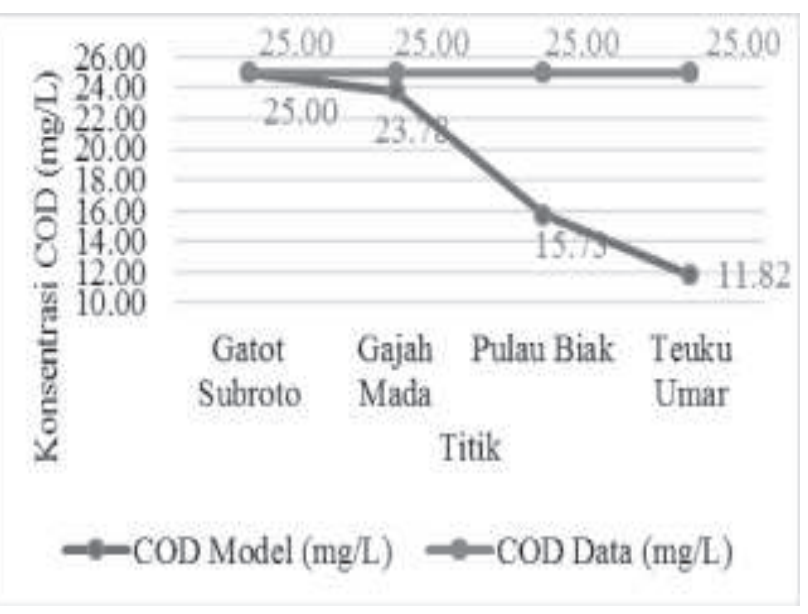

Gambar 9. Simulasi Skenario 3 Parameter COD

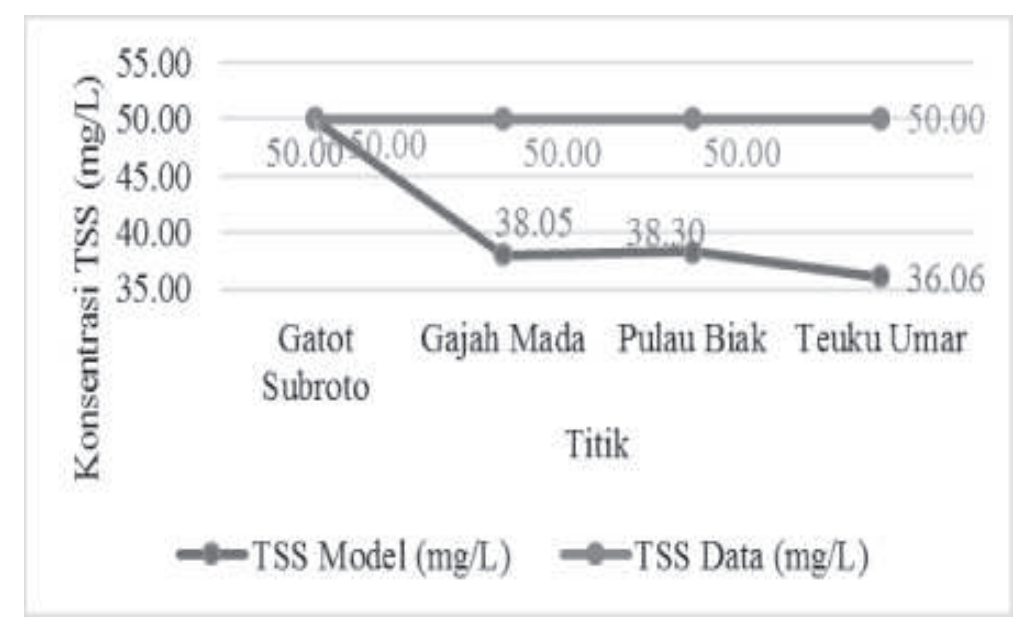

Gambar 10. Simulasi Skenario 3 Parameter TSS

Dilihat dari hasil simulasi skenario 3 yang dimana kualitas air Sungai Badung diasumsikan memenuhi baku mutu air Kelas II dan diasumsikan tidak ada sumber pencemar yang masuk ke Sungai Badung, baik limbah industri maupun limbah domestik. Pada Gambar 8, kandungan parameter BOD dari hulu hingga hilir berada diatas baku mutu air Kelas II, sebesar $3 \mathrm{mg} / \mathrm{L}$. Hasil simulasi untuk parameter BOD semakin mendekati hilir semakin mengalami penurunan kualitas air. Hal ini disebabkan oleh banyaknya pencemar organik yang terdapat di Sungai Badung seperti sampah yang dibuang ke aliran Sungai Badung. Hal ini berkaitan dengan perilaku masyarakat yang masih menjadikan sungai sebagai tempat pembuangan sampah.
Melihat pada parameter COD (Gambar 9) dan parameter TSS (Gambar 10), kandungan COD ataupun TSS pada Sungai Badung tidak melebihi batas ambang baku mutu yang diijinkan.

\subsubsection{Simulasi Skenario 4}

Simulasi skenario 4 adalah sumber pencemar yang masuk pada kondisi telah memenuhi baku mutu lingkungan guna mendapatkan data model sesuai dengan baku mutu kelas dua. Selanjutnya agar kondisi kualitas air sesuai dengan baku mutu, dengan cara mengubah-ubah (trial and error) besar konsentrasi parameter dari point source dan non point source. Hasil dari model simulasi skenario 4 tiap parameter dapat dilihat pada Gambar 11, 12 dan 13. 


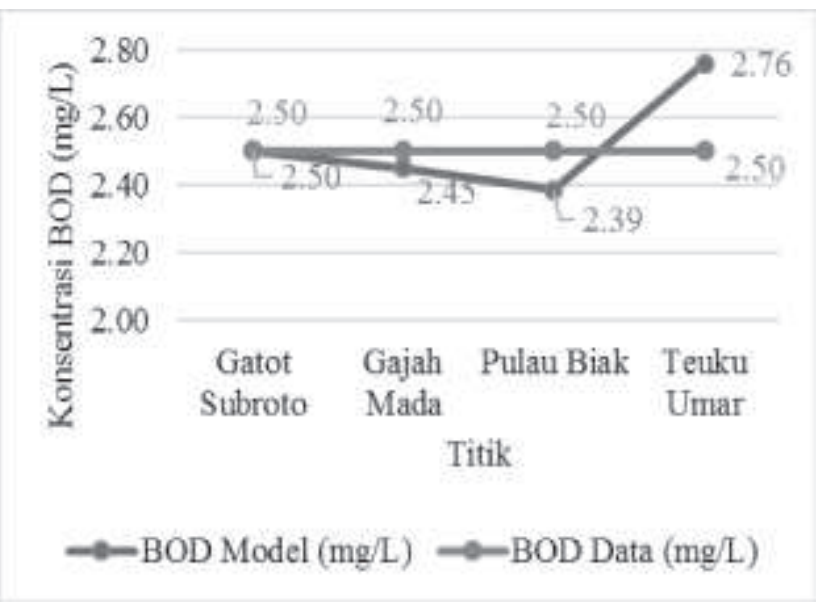

Gambar 11.Simulasi Skenario 4 Parameter BOD

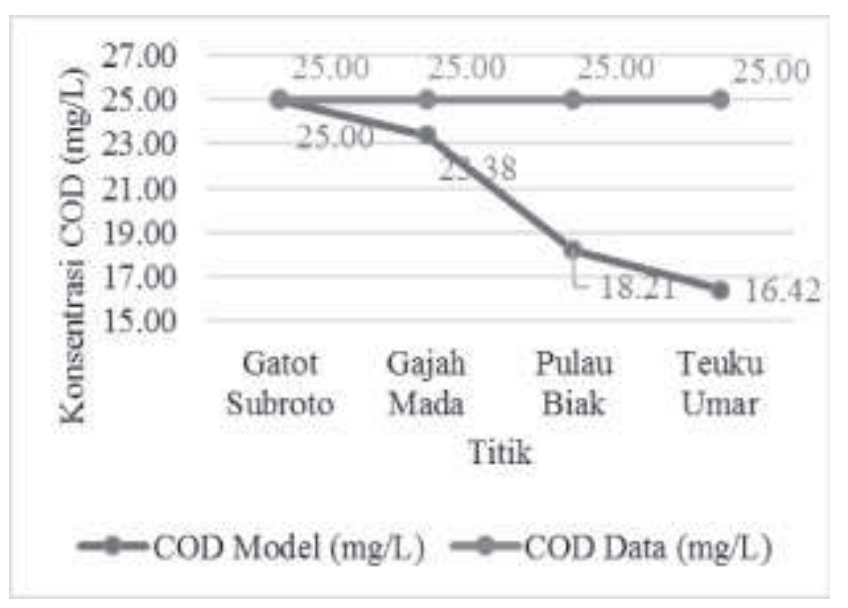

Gambar 12.Simulasi Skenario 4 Parameter COD

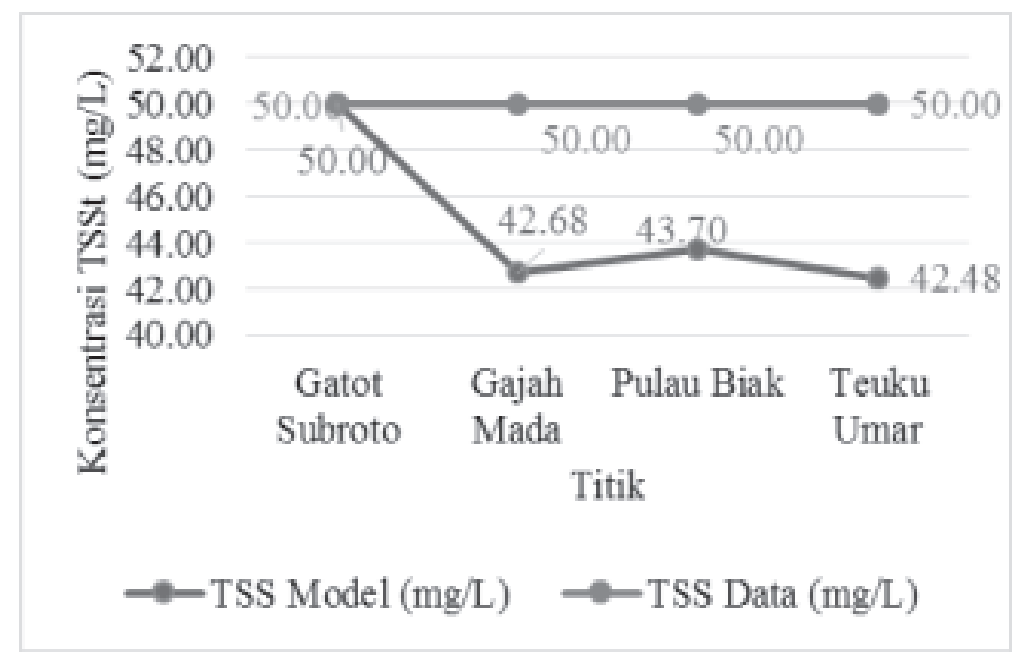

Gambar 13.Simulasi Skenario 4 Parameter TSS

Simulasi skenario 4 adalah kualitas badan air dan bagian hulu diasumsikan memenuhi baku mutu air kelas II, sedangkan untuk besar konsentrasi sumber pencemar dilakukan trial and error hingga didapatkan kualitas air dari sungai memenuhi baku mutu air kelas II. Dari hasil simulasi skenario 4 yang ditunjukkan pada Gambar 5.11 - 5.13 dapat disimpulkan bahwa adanya peningkatan kualitas air Sungai Badung dan sudah memenuhi hasil akhir model yang diharapkan, yaitu memenuhi baku mutu air kelas II.

\subsection{Perhitungan Daya Tampung Beban Pencemaran.}

Perhitungan daya tampung merupakan perhitungan selisih antara kondisi sungai dengan beban pencemar penuh (skenario 4) dan kondisi sungai dengan tanpa beban pencemar yang masuk (skenario 2). Pada skenario 2 merupakan kondisi sungai tanpa adanya beban pencemaran dengan menghilangkan semua sumber pencemar. Sedangkan simulasi skenario 4 merupakan kondisi beban pencemaran yang dikondisikan sesuai dengan baku mutu sungai kelas II. Perhitungan dapat ditulis dengan rumus sebagai berikut:

Daya Tampung $=$ Beban Pencemar Penuh - Beban Kondisi Awal

Contoh perhitungan beban pencemaran pada skenario 2 sebagai berikut:

$\mathrm{BP}=$ Debit $(\mathrm{L} /$ detik $) \times$ Konsentrasi $(\mathrm{mg} / \mathrm{l})$

$=($ Beban Pencemaran $(\mathrm{mg} / \mathrm{L}) \times \mathrm{86.400})$

: 100.000

Debit $=0,62 \mathrm{~m}^{3} /$ detik $=620 \mathrm{~L} /$ detik

Beban Pencemar BOD = Debit $\mathrm{x}$ Konsentrasi

Skenario $2=620 \mathrm{~L} /$ detik x $7,97 \mathrm{mg} / \mathrm{l}$

Beban Pencemar $=4941,40 \mathrm{mg} / \mathrm{detik}=426,94 \mathrm{~kg} /$ hari 
Tabel 2. Beban Pencemaran Skenario 2

\begin{tabular}{ccccc}
\hline Segmen & Jarak $(\mathbf{k m})$ & BOD $(\mathbf{k g} /$ hari) & COD (kg/hari) & TSS (kg/hari) \\
\hline Hulu & 6,08 & 426,94 & 802,98 & 442,47 \\
Segmen 1 & 4,12 & 510,37 & 839,61 & 389,40 \\
Segmen 2 & 2,06 & 441,98 & 569,21 & 399,67 \\
Segmen 3 & 0,00 & 579,70 & 426,71 & 371,98 \\
\hline
\end{tabular}

Tabel 3. Beban Pencemaran Skenario 4

\begin{tabular}{ccccc}
\hline Segmen & Jarak (km) & BOD (kg/hari) & COD (kg/hari) & TSS (kg/hari) \\
\hline Hulu & 6,08 & 133,92 & 1339,20 & 2678,39 \\
Segmen 1 & 4,12 & 194,75 & 1858,32 & 3392,28 \\
Segmen 2 & 2,06 & 216,43 & 1652,19 & 3964,54 \\
Segmen 3 & 0,00 & 300,52 & 1787,04 & 4624,87 \\
\hline
\end{tabular}

Tabel 4. Daya Tampung Beban Pencemaran Sungai Badung

\begin{tabular}{ccccc}
\hline Segmen & Jarak $(\mathbf{k m})$ & BOD $(\mathbf{k g} /$ hari) & COD (kg/hari) & TSS (kg/hari) \\
\hline Hulu & 6,08 & $-293,02$ & 536,21 & 2235,92 \\
Segmen 1 & 4,12 & $-315,62$ & 1018,71 & 3002,88 \\
Segmen 2 & 2,06 & $-225,54$ & 1082,99 & 3564,87 \\
Segmen 3 & 0,00 & $-279,17$ & 1360,32 & 4252,90 \\
\hline
\end{tabular}

Tabel 4 hasil perhitungan daya tampung beban pencemaran maka dapat diketahui daya tampung minimum dan maksimum tiap parameter. Untuk parameter COD daya tampung minimum sebesar $536,21 \mathrm{~kg} / \mathrm{hari}$ pada titik 1 (Jl. Gatot Subroto) sedangkan maksimum 1360,32 kg/hari pada titik 4 (Jl. Teuku Umar). Sedangkan untuk parameter TSS, daya tampung minimum sebesar 2235,92 kg/hari pada titik 1 (Jl. Gatot Subroto) sedangkan maksimum 4252,90 kg/hari pada titik 4 (Jl. Teuku Umar).

Tabel.4. Memperlihatkan pula bahwa Sungai Badung sudah tidak mempunyai daya tampung beban pencemar parameter BOD dari titik 1 (Jl. Gatot Subroto) hingga ke titik 4 (Jl. Teuku Umar) Sungai Badung.

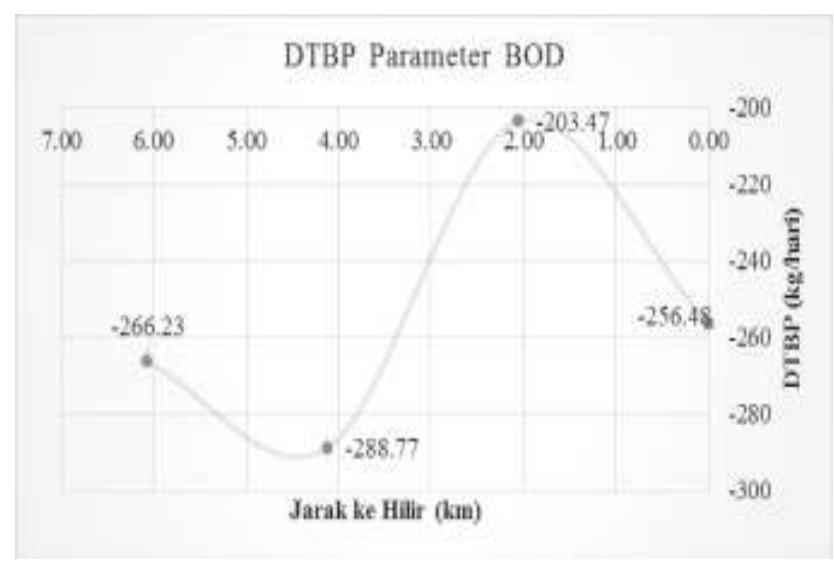

Gambar 14.Grafik DTBP Parameter BOD Sungai Badung
Berdasarkan Gambar 14. Daya tampung beban pencemar parameter BOD Sungai Badung telah melebihi baku mutu yang diizinkan dari titik 1 (Jl. Gatot Subroto) hingga ke titik 4 (Jl. Teuku Umar), dengan kelebihan tiap titik berkisar dari $203,47 \mathrm{~kg} /$ hari sampai $288,77 \mathrm{~kg} /$ hari sehingga perlu dilakukan upaya untuk menurunkan beban pencemar di Sungai Badung wilayah Kota Denpasar khususnya Sungai Badung yang menjadi bagian pada penelitian ini.

\subsection{Perhitungan Daya Tampung Beban Pencemaran.}

Kondisi eksisting Sungai Badung yang telah melewati baku mutu air kelas II untuk parameter BOD yang mengindikasikan perlunya dilakukan penurunan beban pencemar yang masuk ke dalam Sungai Badung. Hal ini karena apabila pada kondisi sebenarnya Sungai Badung tidak mendapatkan pengelolaan yang baik, maka di masa mendatang kualitas air Sungai Badung semakin menurun. Perhitungan penurunan beban pencemar ini membandingkan beban pencemar Sungai Badung dalam keadaan kondisi sebenarnya/eksisting (skenario 1) dengan beban pencemar Sungai Badung yang sesuai dengan baku mutu (skenario 4).

Perhitungan penurunan beban pencemar ini dapat menggunakan persamaan sebagai berikut:

$$
\begin{aligned}
& \text { pemumuman hehon pencemar }(\%) \\
& =\frac{\text { beban pencemaran sken ario } 1 \text { - beban pencemaran skenario } 4}{\text { beban pencemaran skenario } 1} \times 100 \%
\end{aligned}
$$


Contoh Perhitungan untuk titik Jl. Gatot Subroto parameter BOD pada Tabel 5.14:

penurunan beban pencemar $(\%)=$

$$
\begin{aligned}
& \frac{426,94 \mathrm{~kg} / 133,92 \mathrm{~kg}}{\text { hari }} \quad 10 \% \\
& =68,63 \%
\end{aligned}
$$

Penurunan beban pencemar Sungai Badung secara keseluruhan untuk masing-masing segmen dan masing-masing parameter dapat dilihat pada Tabel 5.dan 6.

Berdasarkan hasil perhitungan persentase penurunan beban pencemar maka dapat disimpulkan bahwa untuk parameter BOD diperlukan penurunan yang tinggi. Hal tersebut membuktikan bahwa
1. Daya tampung beban pencemar di Sungai Badung untuk berdasarkan hasil pemodelan adalah sebagai berikut:

a. DTBP Sungai Badung untuk beban BOD telah melewati batas baku mutu yang diizinkan untuk kelas air II, dengan kelebihan tiap titik berkisar dari $203,47 \mathrm{~kg} /$ hari sampai $288,77 \mathrm{~kg} /$ hari.

b. DTBP Sungai Badung untuk beban COD masih berada di bawah batas baku mutu yang diizinkan untuk kelas air II, dengan kemampuan masih dapat menampung beban tiap titik berkisar dari 536,21 kg/hari sampai 1360,32 kg/hari.

c. DTBP Sungai Badung untuk beban TSS masih berada di bawah batas baku mutu yang diizinkan untuk kelas air II, dengan kemampuan masih dapat menampung

Tabel 5. Penurunan Beban Pencemaran Air Sungai Badung

\begin{tabular}{cccccc}
\hline Segmen & Titik & Jarak ke Hilir $(\mathbf{k m})$ & BOD (kg/hari) & COD (kg/hari) & TSS (kg/hari) \\
\hline Hulu & Gatot Subroto & 6,08 & 266,23 & $-536,21$ & $-2235,92$ \\
Segmen 1 & Gajah Mada & 4,12 & 450,24 & $-938,27$ & $-2969,89$ \\
Segmen 2 & Pulau Biak & 2,06 & 328,26 & $-811,07$ & $-3441,37$ \\
Segmen 3 & Teuku Umar & 0,00 & 388,70 & $-1033,34$ & $-4098,57$ \\
\hline
\end{tabular}

\begin{tabular}{|c|c|c|c|c|c|}
\hline Segmen & Titik & Jarak ke Hilir (km) & BOD (\%) & COD (\%) & TSS (\%) \\
\hline Hulu & Gatot Subroto & 6,08 & 62,36 & $-66,78$ & $-505,33$ \\
\hline Segmen 1 & Gajah Mada & 4,12 & 67,02 & $-101,98$ & $-703,11$ \\
\hline Segmen 2 & Pulau Biak & 2,06 & 57,92 & $-96,43$ & $-657,79$ \\
\hline Segmen 3 & Teuku Umar & 0,00 & 54,60 & $-137,10$ & $-778,75$ \\
\hline
\end{tabular}

Tabel 6. Persentase Penurunan Beban Pencemaran Air Sungai Badung

kondisi kualitas air di Sungai Badung tercemar yang sesuai dengan kondisi badan air saat ini. Pengurangan beban secara alami bisa terjadi karena proses self purification dan masuknya sejumlah air ke badan sungai dari air tanah dan aliran anak sungai dengan kualitas yang lebih baik dari badan sungai. Namun demikian pengurangan beban pencemar secara alami itu belum bisa mengimbangi laju beban yang masuk dalam tiap segmen, sehingga diperlukan upaya pengolahan dan pencegahan agar kondisi kualitas air di masa yang akan datang dapat lebih baik. Beberapa upaya untuk mengendalikan kualitas air Sungai Badung agar bisa memenuhi baku mutu.

\section{SIMPULAN DAN SARAN}

\subsection{Simpulan}

Berdasarkan hasil penelitian dan pembahasan dapat disimpulkan beberapa hal yaitu: beban tiap titik berkisar dari 2235,92 kg/ hari sampai 4252,90 kg/hari.

2. Berdasarkan analisa peta penggunaan tata ruang dan karakteristik sumber pencemar Sungai Badung, maka kegiatan/aktivitas yang berpotensi memberi masukan limbah ke badan Sungai Badung sehingga menyebabkan pencemaran antara lain; masukan limbah pada segmen 1 berasal dari permukiman, penginapan, bengkel, perkantoran dan limbah yang terakumulasi pada anak Sungai Jurang. Limbah pada segmen 2 berasal dari permukiman dan limbah yang terakumulasi pada anak Sungai Kelandis dan limbah pada segmen 3 berasal dari permukiman dan berbagai aktivitas usaha rumah tangga yang ada di sekitarnya.

\subsection{Saran}

1. Adanya kajian daya tampung beban pencemaran lebih lanjut di Sungai Badung dengan penambahan simulasi skenario (seperti skenario 
pertambahan penduduk pada 5 tahun mendatang), penambahan parameter yang dianalisis, penambahan data series penelitian yang lebih lengkap (data series penelitian selama setahun) dan analisis pada kondisi kualitas air yang berbeda seperti simulasi kualitas air dengan kondisi Sungai Badung pada saat musim kemarau dan musim hujan.

2. Dibutuhkan upaya pengendalian pencemaran air Sungai Badung dengan memperhatikan kondisi kualitas air dengan memperhatikan aktivitas masyarakat ataupun kegiatan lain yang ada di sekitar aliran Sungai Badung. Hal ini terkait dengan hasil penelitian ini yang menunjukan untuk beban BOD di seluruh titik yang menjadi sampel penelitian ini telah melebihi baku mutu yang di izinkan oleh peraturan yang berlaku.

\section{DAFTAR PUSTAKA}

As-syakur,A.R., I W. Suarna, I W.S. Adnyana, I W. Rusna, I.A.A. Laksmiwati dan I W.Diara.2010.Studi Perubahan Penggunaan Lahan di DAS Badung.Jurnal Bumi Lestari.10(2):200-207.
Badan Lingkungan Hidup Provinsi Bali. 2013. Hasil Pemantauan Kualitas Air Tahun 2013. Provinsi Bali

Effendi, H. 2003. Telaah Kualitas Air Bagi Pengelolaan Sumber daya dan Lingkungan Perairan. Kanisius. Yogyakarta.

Eryani,I.G.A.P.,I Nengah Sinarta dan I Nyoman Surayasa.2014. Perubahan Fungsi Lahan Di Muara Sungai Terhadap Pelestarian Sumber Daya Air.Jurnal Bumi Lestari.14(1):85-90.

Sugiharto, 2014. Kajian Total Daya Tampung Beban Pencemaran Harian Menggunakan Permodelan Qual2k Untuk Pencemar BOD, TSS, Ammonia, Fosfat dan Nitrat di Sungai Kampung Bugis, Tarakan. Jurnal Manusia dan Lingkungan, Vol. 21, No.1, Maret 2014: 21-29

Wiarta, 2008. Analisis Hidraulika Banjir Tukad Badung. Jurnal Forum Teknik Sipil No.XVIII 2008, 851 - 858. Dinas Pekerjaan Umum Bali.

Wiwoho.2005."Model Identifikasi Daya Tampung Beban Cemaran Sungai dengan Qual2E" (tesis).Semarang: Universitas Diponegoro 